\title{
Recent Trends in Japanese Refractories Technology*
}

\section{By Takeshi HAYASHI**}

\section{Introduction}

Receiving the Asada Prize at the 100th Lecture Meeting of the Iron and Steel Institute of Japan is a great honor for me since I have worked in the manufacturing and development of refractories for a long time. As a person who is working in a supplementary industry, I was extremely happy that I was involved in a period of dynamic progress in steel making technology and had the opportunity to work with many creative people under their help.

Refractories technology in Japan has progressed surprisingly fast in recent years, and this has been noted overseas. This progress was led by the rapid progress in Japanese steel making technology. The leadership position of the steel industry over the progress in refractories technology will become even more apparent in the forthcoming years. The entire refractory industry today, however, faces many difficult technological and industrial problems. The industry is now at the most important turning point in its history. On the raw materials aspect, there are problems in resources and in energy. Difficult manufacturing requirements include the demand for increased productivity and the division of refractories into functional refractories for specific application and unshaped refractories for general purposes. Materials requirements include meeting increasingly severe operating conditions required by the new iron and steel making technology and using less energy. In a correlated technology around furnaces, requirements include new construction and dismantling technologies as well as technologies to improve the working environment, countermeasures against dusts, structural design of disposal furnaces for waste materials and handling of various problems in furnace operation. All of these problems are very important and answers for them have to be found in the near future. All of these problems are a common subject of interest for both manufacturers and users of refractories, and close cooperation between them will become increasingly important.

Detailed descriptions of the history and recent progress in refractories have already been given for each specific type of furnace ${ }^{1-5}$ ) and therefore will not be repeated in this presentation. This discussion will be focused on today's problems, such as the characteristics and direction of new refractories technology.

\section{Progress in Refractories Technology}

Approximately $70 \%$ of all refractories are used in steel making. As shown in Fig. 1, total production of refractories increased significantly as the production of crude steel increased during the period 1960 to 1973. Since the oil crisis, however, production decreased sharply. Refractories for construction of blast furnaces and so on decreased, and the large portion of refractories produced in Japan was used for running work. New technologies were developed and various types of refining furnaces, such as AOD, $\mathrm{RH}, \mathrm{DH}, \mathrm{VOD}$ and LF furnaces, and bottom blown converters were introduced. There was also a progress in continuous casting methods and a strong movement towards reducing the amount of refractories per unit production of steel. The quality of refractories technology had to be changed significantly to meet the endless demands set by these new developments in steel making technology. There has been a drastic change in refractories technology in recent years. Strong demands are emphasized in various fields; they include extended service life of blast furnaces, rationalization, improvement of working environment, energy saving and production of steel with higher quality. Many technologies were developed at individual steel plants to meet their specific demands. The characteristics especially noted in the recent trend is the development of new systems as well as new

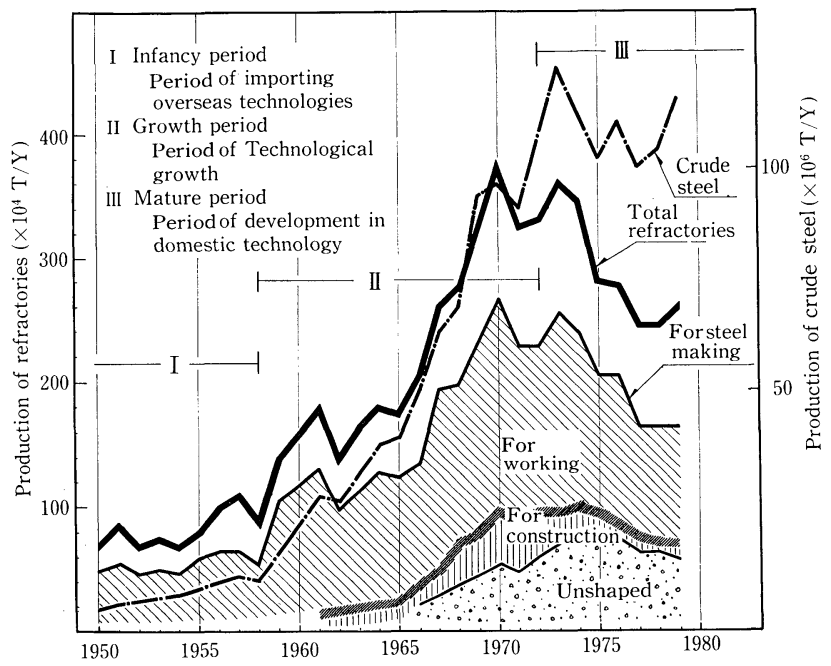

Fig. 1. Change in the annual production of refractories.

* Based on the Special Lecture delivered by Dr. Hayashi in commemoration of his receipt of Asada Prize at the 100th ISIJ Meeting at Kyushu University, Higashi-ku, Fukuoka 812, on October 18, 1980; and published in Tetsu-to-Hagané, 67 (1981), 841, in Japanese. English version received March 16, 1981.

** Senior Managing Director, Shinagawa Refractories Co., Ltd., Otemachi, Chiyoda-ku, Tokyo 100. 
materials, such as basic lining material, refractories applied by casting and gunning, thermal insulating board, refractories for flow control of molten steel and those for injection. Progress in both materials and systems is now being pushed.

The change in refractories unit consumption in Japan is compared in Fig. 2 with that in the United States and West Germany. ${ }^{6-8}$ ) It decreased sharply after 1974 in Japan and became significantly less than in both the United States and West Germany. In Japan, a level of $9.5 \mathrm{~kg} / \mathrm{t}$-steel has been achieved for shaped refractories and $14.9 \mathrm{~kg} / \mathrm{t}$-steel for total refractories used including unshaped refractories.

Table ${ }^{16)}$ shows the annual change in productivity $(\mathrm{t} /$ month) which is a measure of the production technology. Significant improvement is shown for the decade starting in 1960. Improvement of production facilities, introduction of unburned bricks, increased production of unshaped refractories, and rapid growth in the total production contributed to this improvement in productivity. However, the refractories industry has encountered a serious problem in the last 10 years i.e. no significant increases in productivity have been made even with the increased production of unshaped refractories.

\section{Structure and Change of Refractories Tech- nology}

This section discusses the characteristics and structural changes in refractories technology. In looking over the historical change of refractories technology after World War II, the influence of three strong im-

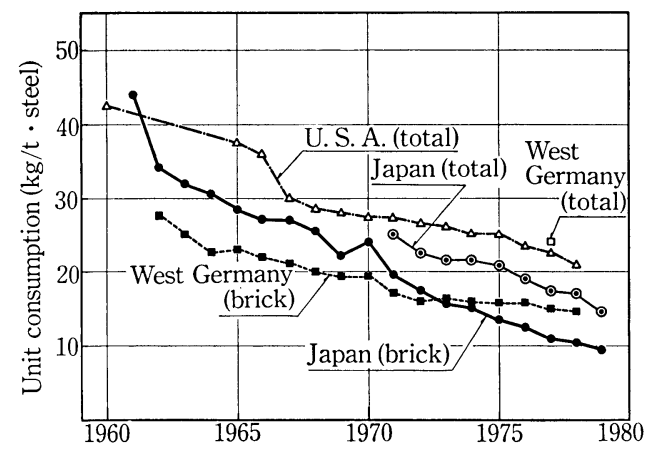

Fig. 2. Annual change in the refractories unit consumption.

Table 1. Change of productivity.

\begin{tabular}{|c|c|c|c|c|c|}
\hline & & 1960 & 1970 & 1975 & 1979 \\
\hline \multirow{3}{*}{$\begin{array}{l}\text { Yield of } \\
\text { refractories } \\
\left(\times 10^{3} \text { t/year }\right)\end{array}$} & brick & 1522 & 2969 & 1998 & 1657 \\
\hline & unshaped & 26 & 679 & 892 & 865 \\
\hline & total & 1548 & 3648 & 2890 & 2552 \\
\hline \multicolumn{2}{|c|}{ Number of employee } & 23000 & 25500 & 22100 & 17300 \\
\hline \multirow{3}{*}{$\begin{array}{l}\text { Productivity } \\
\text { (t/man-month) }\end{array}$} & brick & 5.5 & 9.7 & 9.5 & 8.5 \\
\hline & unshaped & - & - & 29.4 & 27.2 \\
\hline & average & 5.6 & 11.9 & 10.9 & 12.1 \\
\hline
\end{tabular}

pacts is apparent on its development, namely the introduction of overseas technology, new technology developed by the domestic steel manufacturers, and the new trends in the social environment. (see Fig. 3)

A team of representatives from the Japanese steel industry visited the United States in 1950. On their return to Japan, they stressed that the refractories technology in Japan was a serious drawback to progress. This led to the import of excellent refractories. Import started with dense clay bricks for blast furnaces, basic bricks for open hearth furnaces, nozzles for large ladles and carbon stoppers. These materials made a strong impact on the refractories manufacturers in Japan, and domestic production of these refractories became an urgent item. Rapid progress started in domestic steel making technology in 1960's. A wide variety of new refractories optimized for specific application purposes were developed and many new application techniques for them were also established during this period. New materials and new systems were introduced. However, the key points in their development mostly depended on imported technology. Materials developed during this period are direct bonded magnesia chrome bricks, fused silica nozzles, plastic and castable refractories, and the new systems developed are sliding nozzle, slinger and gunning techniques. New domestic technologies also appeared in this period. Examples of them are high purity magnesia clinker, synthetic magnesia dolomite clinker, magnesia carbon bricks, castable refractories for blast furnace troughs and ladles, vibration method, automatic stamping machines and special functional refractories for continuous casting.

In recent years, social and environmental requirements have had an impact on the refractories technology. These include saving energy, resources, and manpower, countermeasures for dust, recycling of waste materials, and re-consideration on using natural raw materials.

That the history of refractories technology is full of improvements and innovation that were necessary to meet the specifications required by increasingly severe operating conditions. The relationship between the severity of operating conditions and the wear rate of refractories has been discussed by Sugita. ${ }^{4}$ Figure 4 shows an example. Under given operating conditions, improvements are designed to enhance the durability and to reduce the unit consumption within material group A. As the operational conditions become even more severe, improvements in material A

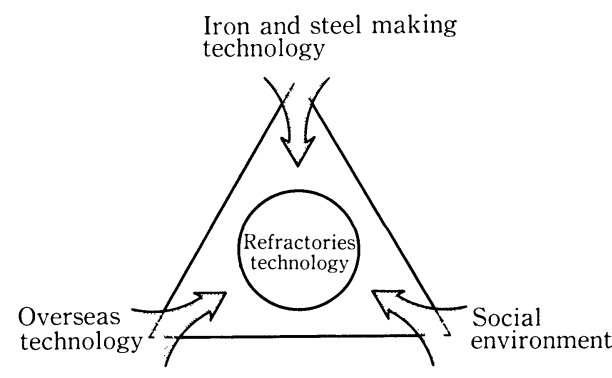

Fig. 3. Impact on refractories technology. 


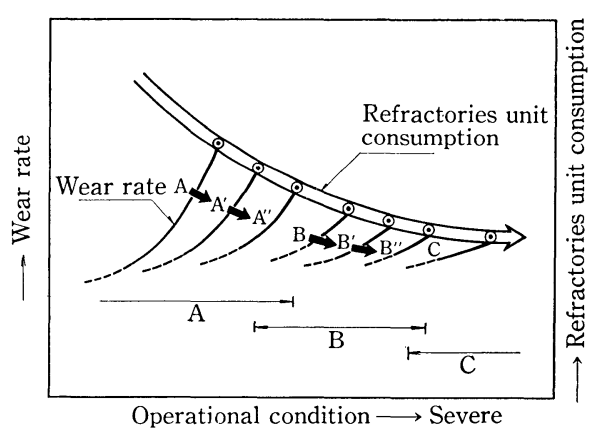

Fig. 4. Pattern in the improvement of refractories and its effect on the refractories unit consumption.

can no longer meet the requirements, and development of another new material B or C starts. This pattern of improvement also involves improving the entire system, not only in materials but also in construction, application, and maintenance technologies. During this process of improvement, reducing the refractories unit consumption has been achieved, and new technologies have been developed. The integrated effects on energy consumption and on steel quality as well as durability and refractories unit consumption will become even more important in evaluating refractories in the future.

Technological aspects of refractories are expressed in various ways. Here, the technologies are divided into the following four groups as shown in Fig. 5; technologies related to raw materials, production process, research and development, and correlated technology. Once, it was said that refractories technology depended almost entirely on technology related to raw materials. Securing good natural raw materials was the key factor for manufacturing a good product, and every manufacturer had their own techniques for preparing good raw materials. This situation corresponds to a technology led by raw materials and is shown by region $\mathrm{A}$ in the figure. However, the nature of refractories technology has changed drastically in recent years. It has moved towards the technology led by the application technology shown by region $B$ in the figure. Both raw material and refractory manufacturers have developed new synthetic raw materials with cooperation because Japan lacks abundant natural resources. A wide variety of raw materials having the necessary purity and density became available and are being used increasingly. These materials include sea-water magnesia, synthetic magnesia-dolomite clinker, magnesia-chrome clinker, synthetic spinel, synthetic mullite, sintered alumina, fused alumina, silicon carbide, fused silica, and zirconia. In accordance with the increasing use of synthetic raw materials, raw materials technology was transferred to specialized raw material producers. Raw materials used by all refractories manufacturers were standardized and characterized technology on raw materials application methods disappeared.

In recent years, an increasing variety of functional refractories and unshaped refractories have come into use. The entire system built around the refractories has become important. This system includes not only

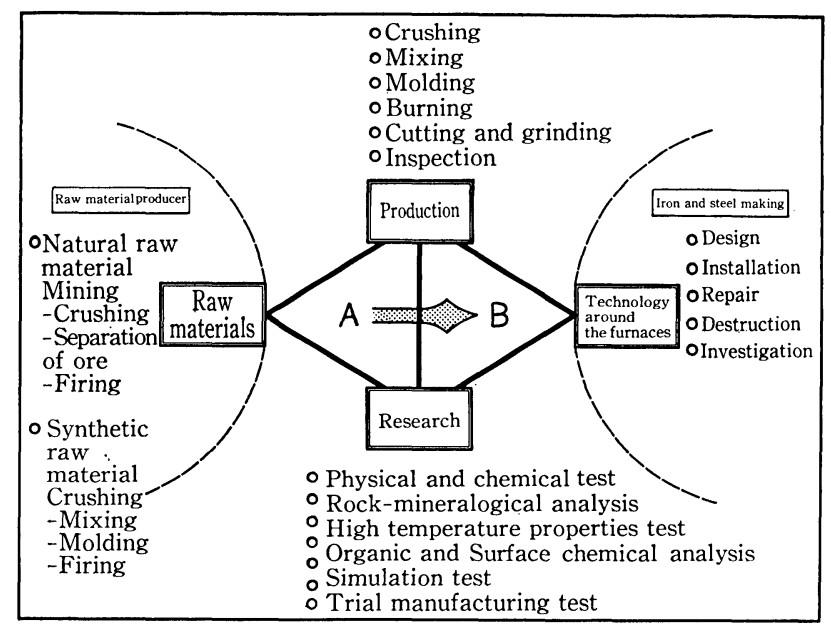

Fig. 5. Structure of refractories technology.

production technology and research and development, but also correlated technology directly related to the users, such as design of furnace, construction, running (operation), measurement, maintenance, and destruction technology. Correlated technology is the interface between users and producers of refractories, and the true value of refractories are evaluated through this technology. Correlated technology is now the source of new technology.

Recently, Japanese refractories technology has received a great attention from overseas refractories engineers. The reason for this is the good cooperation between producers and users of refractories in developing the correlated technology. Their attitude in mutually reporting important achievements has contributed significantly to the development of refractories technology.

The nature and important portion of the refractories technology has changed significantly over the last 30 years. However, the significance of the four factors explained above will not be changed and they will remain necessary for the further development of refractories. Well balanced management between these factors is needed to cope with the variety of situations in which they are used.

\section{Development of Non-oxide Refractories}

Today the refractories technology is at a big turning point. One reason for this is new movement in materials. Figure 6 shows the historical change of principal refractories used for the major parts of iron and steel making furnaces. In all types of furnaces, the variety of refractories used has widened significantly over the last decade. An important point to note here is the increasing use of non-oxide refractories for various applications. Oxide refractories that had been used widely have been replaced by silicon carbide in blast furnaces and magnesia-carbon refractories in electric furnaces. The introduction of these new materials required significant technical innovation in the structure and properties of refractories. Whether the refractories based on oxide materials can be developed further, however, is an important subject that should be considered carefully. Some typi- 
Biast furnace (lower stack)

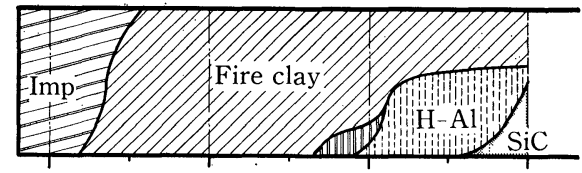

Hot stove (upper part)

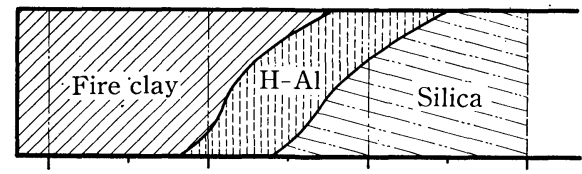

Mixer car (slag line)

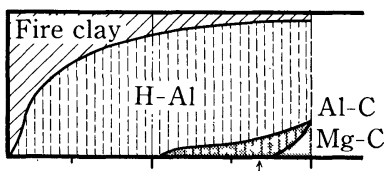

LD converter

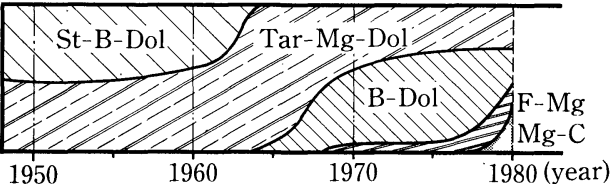

Electric arc furnace (side wail)

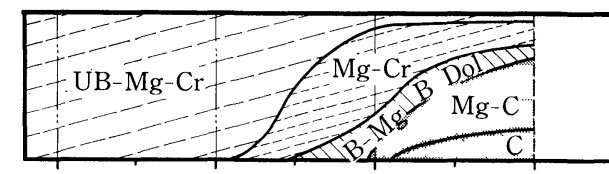

Ladle

Sling or Stamp

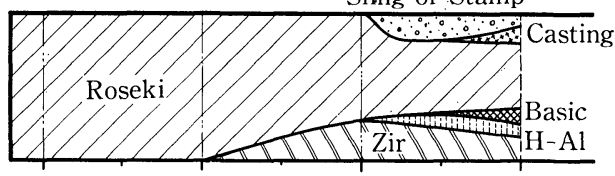

Tundish

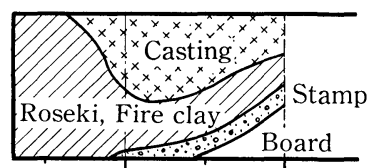

Flow control

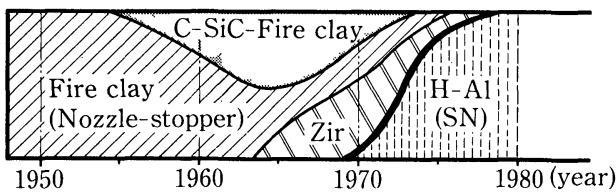

Fig. 6. Change of refractories for iron and steel making.

cal examples for the application of non-oxide refractories are given next.

Damage to the lower stack of blast furnaces greatly affects the life of the furnaces, and the damage mechanism has been studied for a long time. The idea that prevailed since 1923 started that the carbon generated from the decomposition of carbon monoxide was deposited in the structure of refractories and caused the failure. ${ }^{9-11}$ ) Iron oxide in the refractories was believed to act as a catalyst for the carbon deposition. In an attempt to reduce the damage, highly dense low permeability chamotte bricks containing minimal iron oxide were tested as a lining material for blast furnaces. Records showed that their use resulted in no marked improvement in preventing damage to the lower stack. When a boom in construction of large scale blast furnaces started some 10 years ago, the damage mechanism was again studied extensively. Study of failed furnaces and careful analysis in the laboratory showed that the refractories were damaged by reacting with alkali vapor circulating in the blast furnace and not by carbon deposition. ${ }^{12-15}$ ) High purity, high density alumina brick with 95 98\% $\mathrm{Al}_{2} \mathrm{O}_{3}$ was developed to enhance the resistance against the attack by alkali vapor. Only slight improvement in the damage problem was seen with their introduction, however, and actually caused another new trouble. Alumina bricks were damaged by cracking due to their high thermal expansion and high elastic modulus, and therefore did not provide a solution to the problem. Recently, silicon carbide brick has been developed and put into practical use. It has a higher resistance to attack by alkali vapor and also has better cooling characteristics due to its higher thermal conductivity compared to the alumina bricks. The effectiveness of silicon carbide brick in preventing furnace failure has become increasingly recognized in recent years.
Figure 7 shows the modulus of rupture of various refractories at high temperatures in an alkali vapor atmosphere. The resistance against attack by alkali vapor increased in the following order: chamotte bricks, high alumina bricks, alumina bricks, and silicon carbide bricks. Among them, self-bonded silicon carbide bricks and silicon nitride bonded silicon carbide bricks especially showed little degradation in strength and were found excellent. The laboratory results compared favorably with those of actual practice. Their excellence was again proved by a panel test conducted at the Muroran Works of Nippon Steel Corporation, using a real blast furnace. ${ }^{15}$ )

The same conclusion was reached about the same time in the Netherlands, ${ }^{6}$ ) in the United States, ${ }^{7)}$ and in France. ${ }^{8)}$ Thus, the development of silicon carbide bricks was a great break-through in solving troubles at the lower stack. The characteristics of materials used in the refractories for blast furnaces are compared in Table 2. The excellence of silicon carbide is clearly shown.

Bonding texture of silicon carbide brick is different from that of conventional refractories. As shown in Fig. 8, it has fine pores that give outstanding resistance against penetration of molten iron. This microtexture together with low thermal expansion allow the material to be used not only in the lower stack but also in the bottom and hearth. These materials have high thermal conductivity as shown in Fig. 9. Their cooling characteristics are further improved when used in combination with graphite or graphite-silicon carbide bricks. More study in this field is necessary.

Basic bricks for steel making furnaces are discussed next. Basic bricks were introduced around 1952 for the roof of open hearth furnaces. This was an epoc-making event in the history of refractories because they replaced silica bricks and enabled the development of the oxygen steel making process. This 
Table 2. Comparison of properties in refractories for blast furnace.

\begin{tabular}{|c|c|c|c|c|c|c|}
\hline & & $\begin{array}{l}\text { Silicon } \\
\text { carbide }\end{array}$ & $\begin{array}{c}\text { Graphite } \\
\text { silicon carbide }\end{array}$ & Carbon & $\begin{array}{l}\text { High- } \\
\text { alumina }\end{array}$ & Chamotte \\
\hline \multicolumn{2}{|c|}{ Resistance to rupture by thermal stress } & (Q) & (0) & O & $\triangle$ & $x$ \\
\hline \multicolumn{2}{|l|}{ Cooling efficiency } & O & (0) & 0 & $\Delta$ & $x$ \\
\hline \multicolumn{2}{|l|}{ Resistance to alkali } & (2) & $\triangle$ & $\Delta$ & $\mathrm{O}$ & $x$ \\
\hline \multicolumn{2}{|c|}{ Resistance to penetration of molten iron } & (C) & (0) & $x$ & $\mathrm{O}$ & $\triangle$ \\
\hline \multirow{2}{*}{ Corrosion resistance } & $\mathrm{FeO}$ & O & O & $\Delta$ & $\Delta$ & $\Delta$ \\
\hline & $\mathrm{CaO}$ & O & (C) & (a) & O & $\Delta$ \\
\hline \multicolumn{2}{|l|}{ Abrasion resistance } & (C) & $\Delta$ & $\Delta$ & (a) & $\Delta$ \\
\hline \multicolumn{2}{|l|}{ Oxidation resistance } & $\mathrm{O}$ & $\Delta$ & $x$ & (a) & (a) \\
\hline
\end{tabular}

(O): Excellent, $\mathrm{O}:$ Good, $\Delta:$ Fair, $\times:$ Poor

Fig. 7.

Alkali resistance of bricks for blast furnace.

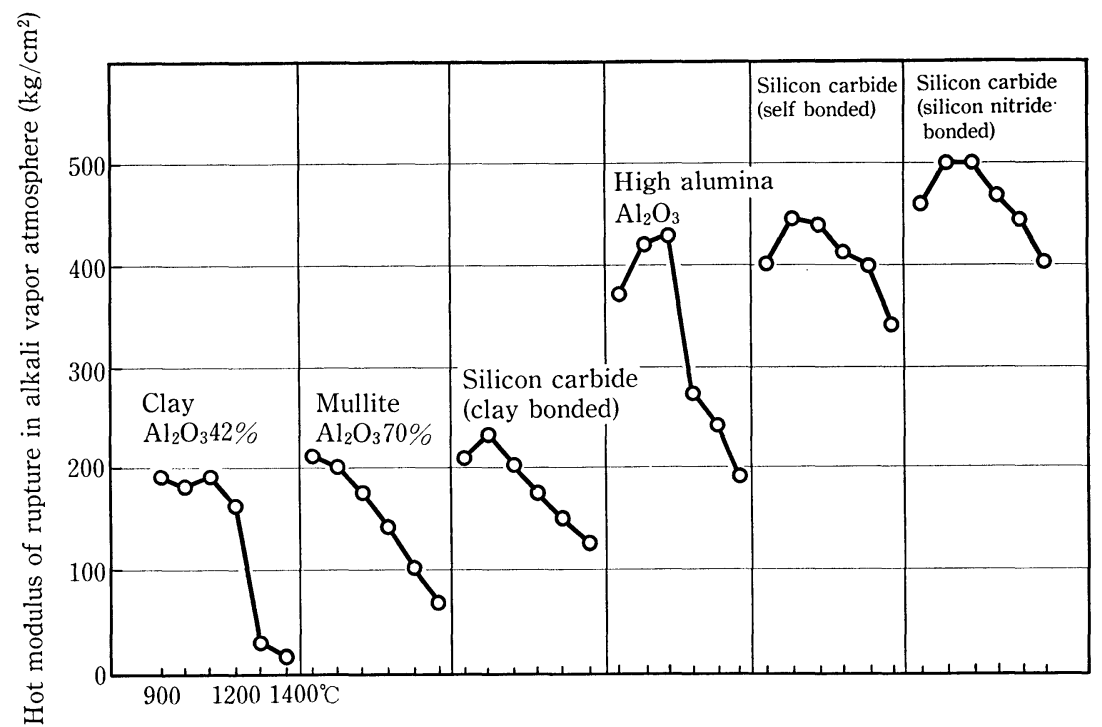

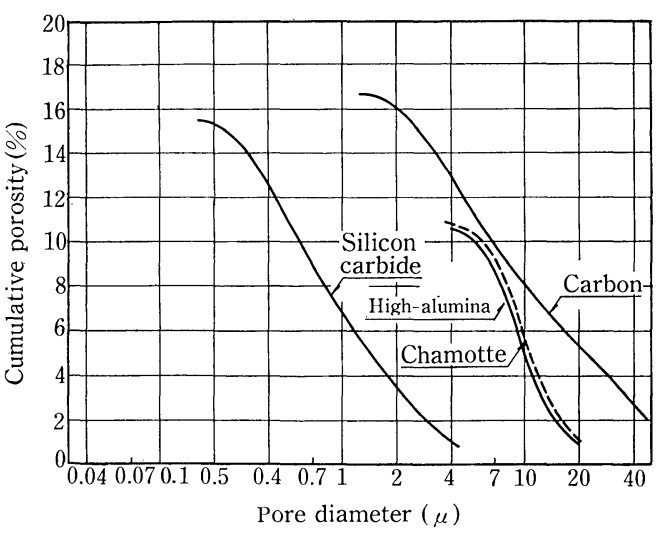

Fig. 8. Pore size distribution in bricks for blast furnace.

achievement was remarkable. The refractories failed frequently, however, and were not completely satisfactory. The problem of peeling was a characteristic of basic bricks and had to be solved. Studies on basic bricks thereafter mostly concentrated on this problem. Failure morphology of typical basic bricks are compared in Photo. 1.

In unburned magnesia chrome brick, slag penetrates deeply from the high temperature side of the

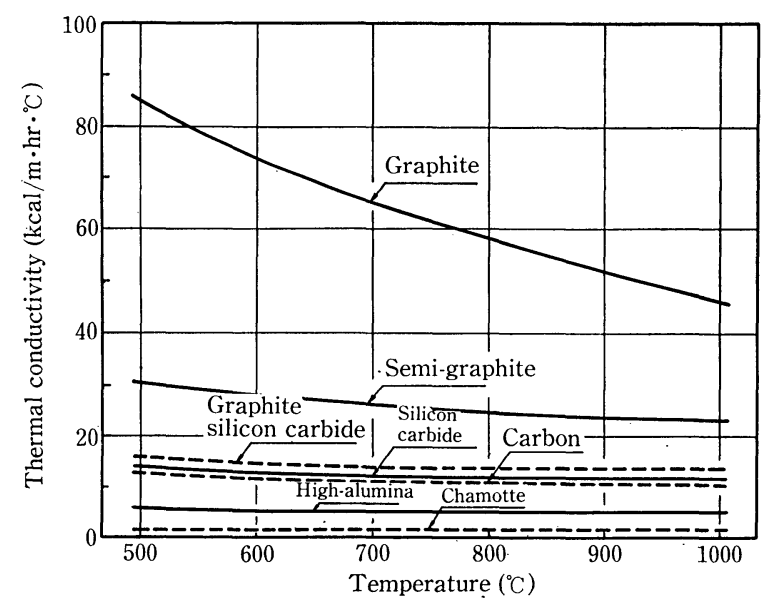

Fig. 9. Thermal conductivity of bricks for blast furnace.

brick, and forms a thick altered layer. Cracks are generated at the boundary between the altered layer and the base brick. Peeling off of the surface from these cracks was the main source of the trouble. Direct bonded magnesia chrome bricks using high purity magnesia and chrome spinel burned at high temperature were developed to prevent the formation 


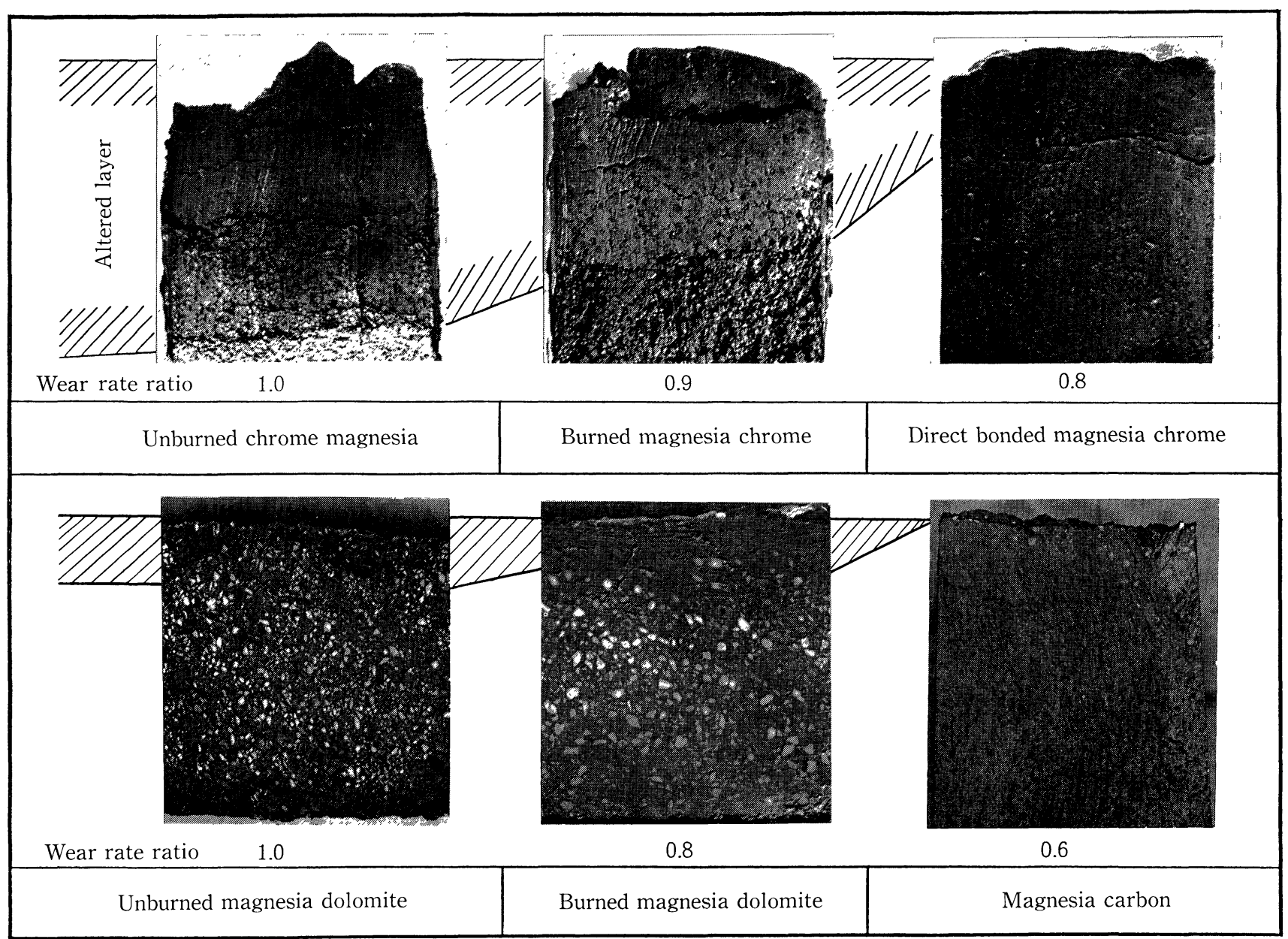

Photo. 1. Damage in basic bricks.

of the altered layer. This brick has a strong and dense microtexture with directly bonded crystalline phases. Direct bonded bricks are gaining a good reputation and are still used as lining materials in electric arc furnaces and ladles for secondary refining. They failed, however, to completely solve the peeling problem. The direct bonding reduced the toughness and tended to cause cracking in some applications. Progress in development reached point where further improvements could no longer be made with this brick. The shortcomings of easy cracking in direct bonded magnesia chrome bricks was overcome by magnesia carbon bricks developed for electric furnaces. ${ }^{19)}$

From a very early stage, tar bonded dolomite bricks were used in LD converters. However, they showed limited durability and were gradually replaced by burned bricks to improve erosion and oxidation resistance. High burned high purity magnesia dolomite bricks came common use. The use of this brick together with improved operating techniques, such as in gunning repair and slag control brought the achievement of converter life to over 10000 cycles. ${ }^{14)}$ However, these burned bricks also suffered damage due to peeling as in the magnesia chrome bricks discussed above and could not solve the problem. Magnesia carbon bricks were again noted to be good lining material in converters. They were used in some converters on an experimental basis and proved satisfactory. Application of magnesia carbon bricks solved the fundamental problems of basic bricks, i.e., erosion by slag and development of cracks. This achievement was quite remarkable. Not burning refractories also contributes to saving energy.

Photograph 2 shows the typical microtextures of these basic bricks. Figure 10 shows the relationship between the elastic modulus, thermal conductivity, the depth of slag penetration and carbon content. Addition of carbon reduces the penetration of slag, and in clear contrast to the conventional belief, separating particles reduce the elastic modulus and give increased thermal spalling resistance and erosion resistance. For example, Photo. 3 shows the microtexture of the working surface of magnesia carbon refractories used in a converter. Penetration of slag is slight and the altered layer is only in the surface region.

However, the magnesia carbon refractories explained thus far have short-comings. Oxidation of carbon and decomposition of magnesia occur during operation. Its high thermal conduction required thermal insulation and cooling facilities to prevent the metastable from over-heating. There is also a shortage of graphite resources. The industry has also had bad experience with the supply of zircon. Careful consideration of resources used is necessary, since the entire 


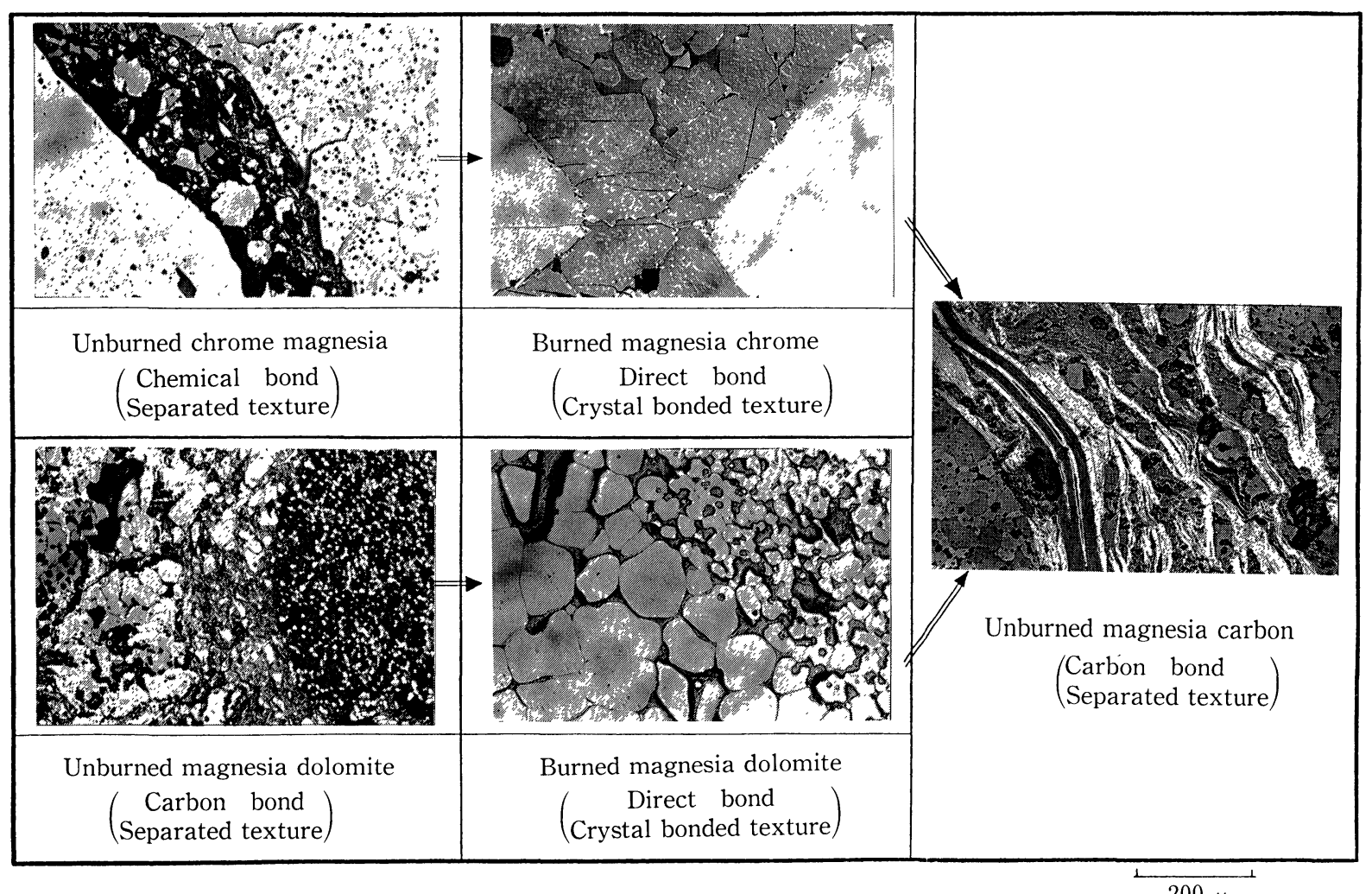

Photo. 2. Bonding texture in basic refractories.

Photo. 3.

Texture in used $\mathrm{MgO}-\mathrm{C}$ brick.

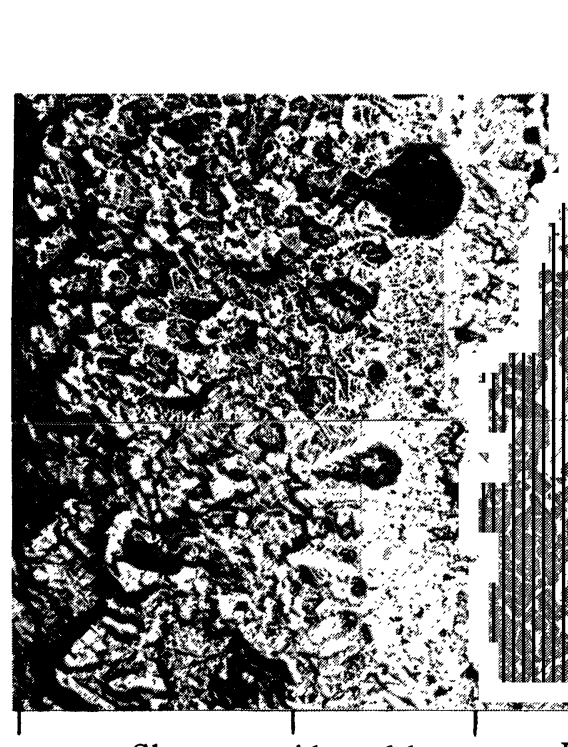

Slag
Altered layer

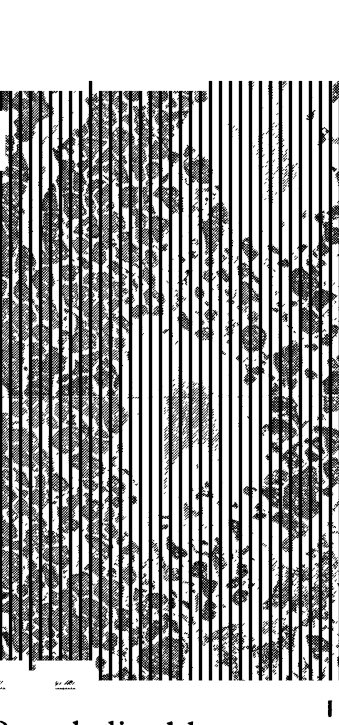

Decarbulized layer

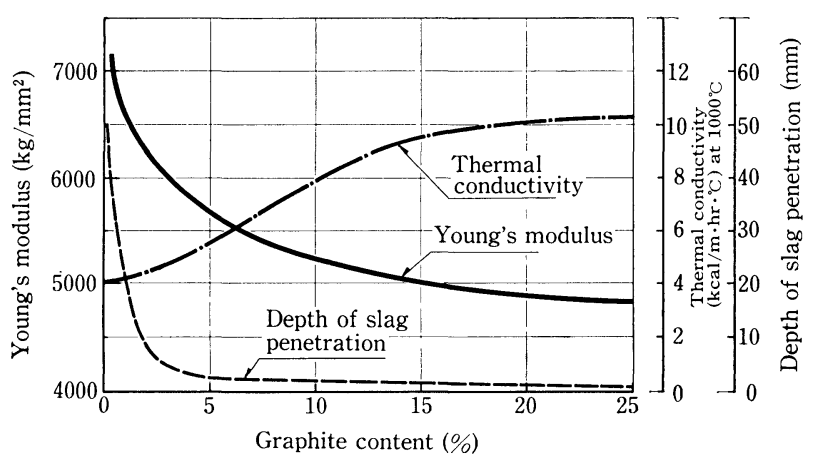

Fig. 10. Effect of graphite in $\mathrm{MgO}-\mathrm{G}$ system. industry depends on imported raw materials that have limited resources.

Through the historical survey given above on the lining materials used in blast furnaces and converters, it was shown that non-oxide refractories can potentially solve many difficulties which oxide refractories can not. Today the territory of refractories should not be limited to only oxide materials. Non-oxide refractories having $\mathrm{Si}, \mathrm{SiC}$, and $\mathrm{G}$ as a main constituent play very important role in it.

Figure 11 shows various systems between carbon and oxides that constitute the major part of refractories. Within each class of oxide refractories, the 
main constituents were diversified into two extreme regions. In the basic refractories, mostly the region characterized by high $\mathrm{MgO}$ content and partly the region having high $\mathrm{CaO}$ content were developed. In the silica-alumina refractories, the region of high alumina or high silica was mainly developed. Developing higher purity and lower flux content was the goal in these refractories, and at the same time, higher density through high pressure molding and high temperature firing was pursued. Through these processes, considerable improvement was achieved in resistance to corrosion and penetration of slag. However, the elastic modulus and thermal expansion coefficient increased, and poorer thermal shock resistance resulted. These problems were solved by using nonoxide refractories having both corrosion resistance and toughness. Examples are silicon carbide, magnesiacarbon, and alumina-carbon bricks.

Such materials developed under the concept explained above are used extensively in the lining for blast furnaces and converters as described earlier. They are also used in blast furnace troughs, electric arc furnaces, refining furnaces, mixer cars, sliding plates, and submerged nozzles.

There is also an exception in the growing popularity of non-oxide refractories. An example for this is silicious bricks. Pyrophyllite bricks, representative of silicious brick, have excellent characteristics and is still a popular lining material for ladles. When it is heated during operation, a liquid phase having high viscosity is formed on the surface. The liquid phase reduces the thermal stress and prevents the penetration of slag. Cracks or uncovered surface are healed by the broaching characteristic of the brick, and the surface of the entire lining is fused together into a single body. As the lining material for the bottom of ladles, pyrophillite bricks outperformed basic bricks, high alumina bricks, and zircon bricks and still maintains clear superiority over them. This brick uses the characteristics of silicate very effectively and is unique in the Japanese refractories industry. It is a natural product and should be especially noted in the history of refractories for steel and ingot making. ${ }^{20-24)}$ How-

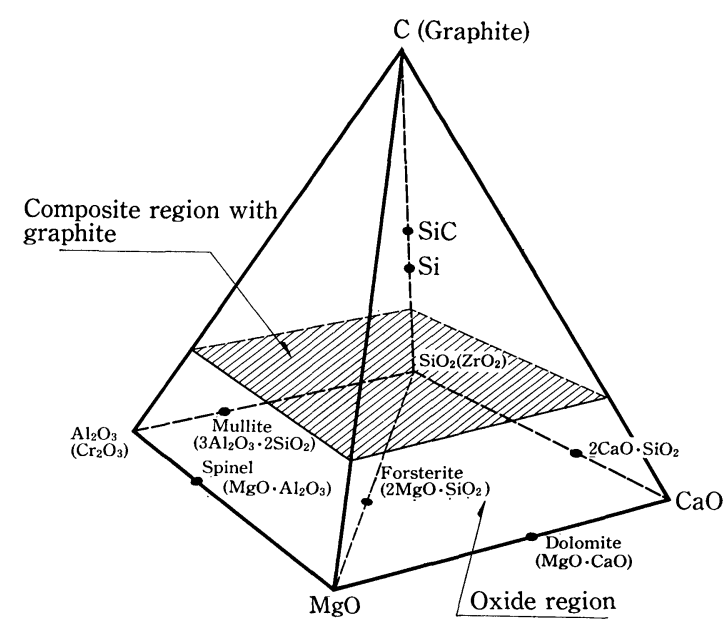

Fig. 11. Development to non-oxide refractories. ever, the extent to which the brick can be used for lining material should be examined carefully by taking into account the increasingly severe operating conditions for ladles and its effect on the quality of steel.

\section{Trends of Refractories foward Higher Quality}

The recent trend of refractories points in two directions. One is unshaped refractories and the other is shaped refractories having higher quality (functional refractories). There are on increasing variety of refractories that play important roles in steel making technology these days. They include various types of refractories for flow control, such as for sliding nozzles, submerged nozzles, porous plugs, and lance pipes. These functional refractories are of critical importance to suitable operation in steel making and on the quality of steel. Higher precision and stability than conventional refractories is required in various properties, such as resistance to spalling and corrosion, gas tightness, permeability, and mechanical properties. As presented in Table 3, fused silica, alumina-carbon, zirconia, silicon nitride, and boron nitride have been developed to meet these requirements.

Special microtextural control is required in these functional refractories to give them specific characteristics. A similar approach used in fine ceramic technology rather than that used in conventional ceramics is necessary in developing these refractories.

As an example, the microtexture of a zirconia nozzle is shown in Photo. 4. The right micrograph shows a uniform structure in conventional brick. In contrast, inclusions of the monoclinic zirconia phase are present at the grain boundary of stabilized zirconia. Thermal shock resistance is improved significantly with this microtexture.

Similarly, as shown in Fig. 12, the thermal spalling property of the silicon nitride nozzle was improved significantly by the presence of boron nitride inclusions at the grain boundary of the silicon nitride phase.

Originally, refractories were made mainly from natural raw materials and consequently were charac-

Table 3. High quality refractories.

\begin{tabular}{|c|c|c|}
\hline Requirement & Material & Application \\
\hline $\begin{array}{l}\text { Thermal shock re- } \\
\text { sistance }\end{array}$ & Fused silica & $\begin{array}{l}\text { Submerged nozzle } \\
\text { Air-seal pipe }\end{array}$ \\
\hline $\begin{array}{l}\text { Corrosion resistance } \\
\text { Thermal shock re- } \\
\text { sistance }\end{array}$ & $\begin{array}{l}\text { Alumina-carbon } \\
\text { Zirconia-carbon } \\
\text { Special unshaped } \\
\text { refractories }\end{array}$ & $\begin{array}{l}\text { Submerged nozzle } \\
\text { Air-seal pipe } \\
\text { Lance pipe }\end{array}$ \\
\hline Gorrosion resistance & $\begin{array}{l}\text { Alumina } \\
\text { Zirconia } \\
\text { Magnesia }\end{array}$ & $\begin{array}{l}\text { Sliding nozzle } \\
\text { Porous plug } \\
\text { Tuyere brick }\end{array}$ \\
\hline $\begin{array}{l}\text { Non-wettability to } \\
\text { molten steel } \\
\text { Hot strength } \\
\text { Mechanical property }\end{array}$ & $\begin{array}{l}\text { Silicon carbide } \\
\text { Silicon nitride } \\
\text { Boron carbide }\end{array}$ & Special nozzle \\
\hline
\end{tabular}


Photo. 4.

Microtexture in stabilized zirconia.

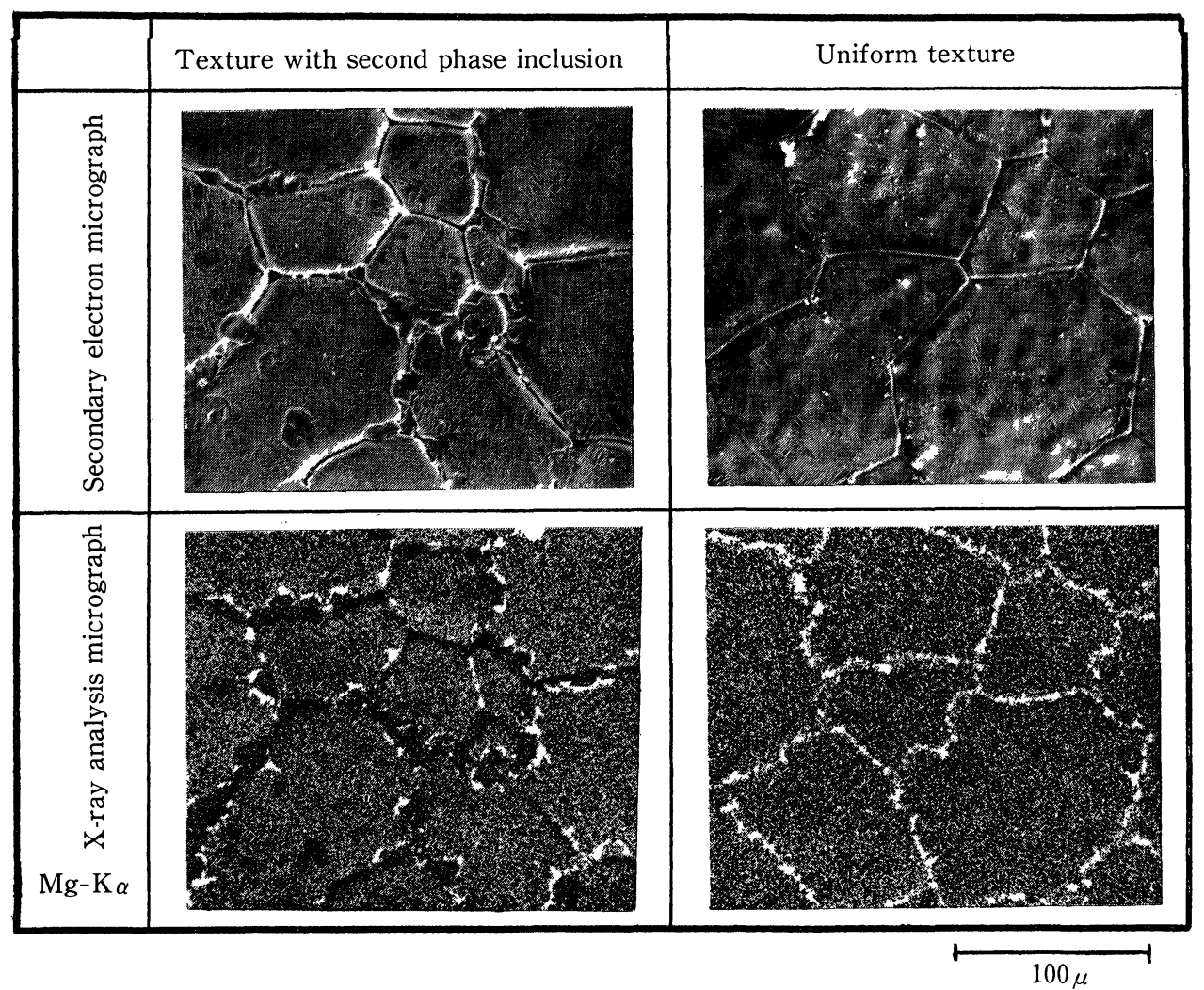

terized by a non-uniform microtexture having crystalline phase, grain boundary phase, and matrix, and a range of shapes, sizes and distributions of grains. Recent trends in refractories, however, point to a more uniform and dense microtexture by using more synthetic raw materials. This microtexture, however, does not necessarily have the same thermal shock resistance. The discovery of improved thermal shock resistance by intentionally incorporating a non-uniform microtexture in the refractories is very significant. Further study is clearly necessary on the microtexture control, such as in bonding morphology, crystal size, and distribution of grain and matrix. Re-examination of natural raw materials from the standpoint described above is a very important subject for further research. It also is the starting point to reform the conventional refractories into fine ceramics.

\section{Evaluation and Test Methods of Refractories}

Refractories are believed to be a typical experienceoriented engineering material in which a priori evaluation is very difficult, and their characteristics can only be understood after use. The extremely complex damage mechanism is responsible for this belief. Refractories are exposed to molten steel and slag at high temperatures and pressure and varying temperature, thus full comprehension of the damage mechanism is very difficult. In the past, numerical representation between the dissipation rate, the operational condition, and the properties of refractories was attempted in refractories for converters and ladles. However, no general relationship has been obtained between them and the equations proposed are applicable only for special cases.

Damage pattern of refractories are divided into
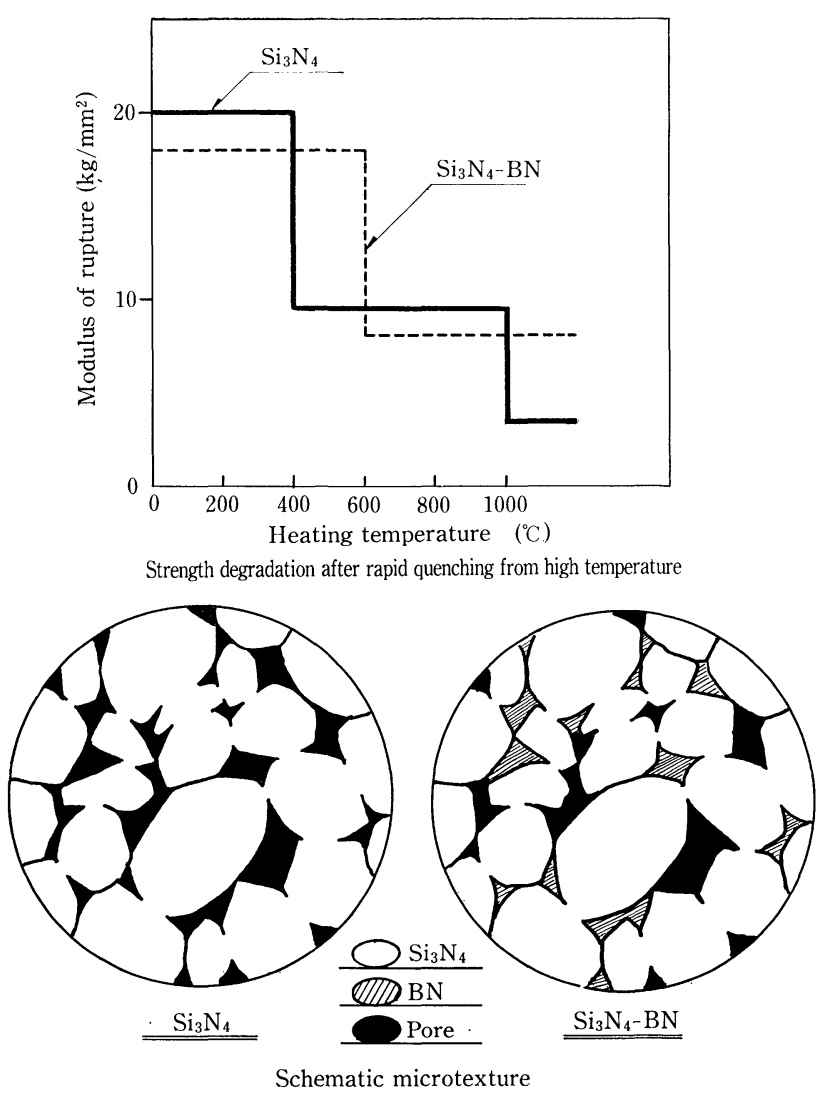

Fig. 12. Thermal shock resistance and microtexture of sintered silicon nitride body.

three groups as shown in Fig. 13. Pattern $I$ is an irregular crack at the back face in which the mechanical and thermal stresses developed in the furnace structure are responsible for the crack (thermal and 
mechanical spalling). In pattern II, a characteristic altered layer having a different microtexture than the original brick is formed at the heated face of the brick by penetration of slag and heat. Cracks develop parallel to the heated face at the boundary of the layer and the brick base (structural spalling). Pattern III is surface erosion of the brick, in which they react with molten steel or slag and form the liquid phase surface and are dissolved away or abraised (damage by dissolution).

Of the three damage mechanisms, patterns I and II make the damage mechanism of refractories more complex and are often the main factors which govern the high dissipation rate of refractories. Elimination of damage caused by these mechanisms is one of the major research objectives in refractories. Experimental and theoretical studies on factors related to the furnace body are done mainly by the refractories users. The mechanism of crack formation by thermal stress is being studied and structural analysis of furnace bodies is progressing rapidly. ${ }^{23-25)}$ The research efforts by producers of refractories resulted in clarifying the toughness of refractories and the development of non-oxide refractories. These efforts contribute significantly to the understanding of the damage mechanism and the development of countermeasures against cracks. Now, improvement against pattern I damage is apparent. Damage by pattern II has been the critical fault common in basic bricks as well as in other high quality bricks. Development of magnesiacarbon refractories and other non-oxide refractories improved the damage problem significantly. Damage is limited to within the surface layer in these bricks. The contribution of these non-oxide refractories in improving pattern II damage is remarkable.

Similarly, elimination of wear due to irregular cracks is expected to make a priori evaluation of refractories much easier. Thus, the meaning of numerical value characteristics for a given refractory and the correlation between the laboratory erosion test and practical results will become much more clear. Dynamic tests using the simulation on the furnace body will make a priori evaluation of refractories even more practical and will enable accurate numerical representation of the dissipation rate under various conditions. In the research of refractories, this is one of the final objectives for both users and producers.

\section{Conclusion}

Recent trends in refractories technology have been discussed with the topics on non-oxide refractories as the central subject. Limited time did not allow full discussion of the trends in various important and related fields. Trends in refractories technology involved for each specific type of furnace and those for unshaped refractories as well as problems in the production of refractories were not discussed. Refractories technology covers a wide range of engineering fields and involves many difficult problems. Hereafter, further progress is expected to be made in iron and steel making technology. Much more severe requirements will be imposed on refractories. An attitude of cooperation between users and producers is increasingly important in developing correlated and other important technologies in refractories. Finally, as a summary of this presentation, the author would like to emphasize two important points.

First, the possibility of oxides constituting the major part of conventional refractories has apparently reached to a limit in the recent trend. Studies show that oxides are being replaced by non-oxide refractories, such as silicon carbide, silicon nitride, and graphite. Does this mean that the oxide refractories have reached to their true end point? This problem requires careful consideration. Non-oxide refractories have already encountered several difficulties in finding sufficient resources and in high energy consumption during production. On the other hand, oxide refractories can still be used in many fields. Resources of raw material for oxide refractories are still abundant, and when used as refractories, they are essentially stable. With these points taken into account, the author believes that they should not be abandoned, rather their effective utilization should be studied further. Application technology must be developed in which oxide and non-oxide refractories are used as composite materials.

The second point is cooling. A well-known refrac-

\begin{tabular}{|c|c|c|c|}
\hline Pattern & Phenomena & Morphology of wear & $\begin{array}{l}\text { Schematic } \\
\text { representation }\end{array}$ \\
\hline$I$ & $\begin{array}{l}\text { Irregular back face crack } \\
\text { Thermal stress strain in } \\
\text { furnace body } \\
\text { Temperature change }\end{array}$ & $\begin{array}{l}\text { o Development of crack } \\
\text { and falling off } \\
\text { (Spalling) } \\
\text { o Penetration of molten } \\
\text { iron and steel } \\
\text { Gas leak }\end{array}$ & 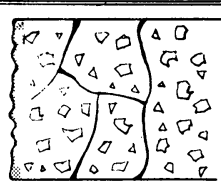 \\
\hline II & $\begin{array}{l}\text { Crack in parallel to hot } \\
\text { face } \\
\text { Formation of altered layer } \\
\text { Penetration of flux }\end{array}$ & $\begin{array}{l}\circ \text { Growth of crack } \\
\text { Peeling of } \\
\text { [high wear rate] }\end{array}$ & 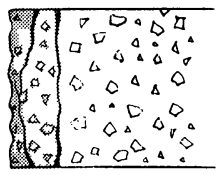 \\
\hline III & $\begin{array}{l}\text { Erosion of surface layer } \\
\text { Disintegration of bonding } \\
\text { texture } \\
\text { Penetration of flux }\end{array}$ & $\begin{array}{l}\circ \text { Liquidus flow } \\
\text { Separation } \\
\text { erosion } \\
\text { [low wear rate] }\end{array}$ & 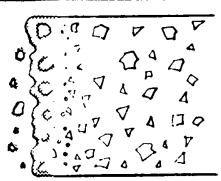 \\
\hline
\end{tabular}

Fig. 13. Damage pattern in refractories. 
tories engineer said, "Water is the best refractory of all". This is indeed true, and water cooling is very effective in blast furnaces and electric furnaces. Development of non-oxide refractories and higher quality refractories coincide with higher thermal conductivity. Cooling can even be one of the ultimate points in refractories. How far cooling is possible and how it should be balanced with other properties of refractories are another subject that needs further examination. Before making the final conclusion that the water is the best refractory, however, we must recognize that there are many difficult technological tasks that need to be accomplished in refractories development. This challenge is the objective that today's users and producers of refractories must work toward.

\section{REFERENCES}

1) T. Hayashi: Tetsu-to-Hagané, 56 (1970), 1089.

2) N. Katada, K. Sugita and Y. Mizutani: Seitetsu Kenkyu, (1975), No. 283, 1.

3) Y. Mizutani, T. Nomura, H. Shibata and T. Oosaki: Ceramic Data Book, Kogyo Seihin Gijutsu Kyokai, (1976), No. $56,145$.

4) K. Sugita: Tetsu-to-Hagané, 65 (1979), 1462.

5) N. Katada, K. Sugita and H. Shibata: Metals and Tech nology, 49 (1979), 2.

6) Taikabutsu Kyokai Kaiho, ed. by The Japan Ref. Assoc., (1980), No. 361, 5.

7) L. A. Leonard: Ref. Jour., (1978), No. 5, 12.
8) M. Koltermann: Radex-Rundschau, (1979), No. 4, 1120.

9) T. F. Berry, R. N. Ames and R. B. Snow: J. Amer. Ceram. Soc., 39 (1956), 308.

10) W. R. Davis, R. J. Slawson and G. R. Rigby: Trans. Brit. Ceram. Soc., 56 (1957), 67.

11) T. Hayashi: Tetsu-to-Hagané, 53 (1967), 1176.

12) T. Hayashi and M. Shibuno: Tetsu-to-Hagané, 56 (1970), S379.

13) T. Hayashi, M. Shibuno, T. Fujiwara and O. Sawaki: Tetsu-to-Hagané, 62 (1976), S451.

14) K. Hiragushi: The 48th and 49th Nishiyama Memorial Lecture, ISIJ, (1977), 31.

15) K. Hiragushi: Refractories, 29 (1977), 403.

16) J. T. Vau Kongnenburg and J. Van Laar: Iron \& Steel Eng., 53 (1976), No. 6, 57.

17) R. H. Herron and K. A. Baab: Amer. Ceram. Soc. Bull., 54 (1975), 654.

18) L. Halm: Rev. Met., 77 (1980), No. 2, 121.

19) Y. Nishiyama, A. Watanabe and Y. Kusaka: Refractories, 25 (1973), 42.

20) T. Hayashi: Imono (J. Japan Foundrymen's Soc.), 30 (1958), 1.

21) T. Hayashi: The 48th and 49th Nishiyama Memorial Lecture, ISIJ, (1977), 113.

22) T. Hayashi, Y. Kyoden and Y. Namba: Refractories, 22 (1970), 211.

23) S. Uchiyama: Refractories, 32 (1980), 539.

24) M. Kumagai and R. Uchimura: Refractories, 11 (1980), 601.

25) I. Kato, Y. Morita and F. Uegami: Refractories, 32 (1980), 661. 